\title{
İş Dünyasında Maverick Liderlik ve Z Kuşağı İncelemesi
}

DOI: $10.26466 /$ opus.771231

$*$

\author{
Ayla Avc1 * \\ * İstanbul Sabahattin Zaim Üniveritesi, İşletme Bölümü, İstanbul \\ E-Posta: aylaavci@windowslive.com \\ ORCID: 0000-0002-1871-4090
}

\begin{abstract}
Öz
Liderler her dönemde insanlara yön veren, çizdiği hedeflere ulaştıran kişilerdir. Toplumlar, kendilerini daha iyiye, daha refaha kavuşturmak için kendilerine lider seçerler. İşletmeler de uzun vadede sürdürülebilirlik ve kahıcı müşteri ilişkileri sağlamak amacıyla modern, çağdaş lider bulma arayışlarındadırlar. Günümüzde teknolojiyi kurumlarında en iyi şekilde kullanabilen şirketler ayakta kalmaktadır. Dolayısıyla bu teknolojileri de en iyi yöneten liderler şirketleri geleceğe taşıyarak, canlı bir varlık gibi görülen organizasyonların yaşamaların sürdürmelerinde etkili olmaktadır. Günümüz küresel rekabet ortamlarında farklı ürün ve hizmet anlayışıyla müşterilerin ihtiyaçlarını giderme anlayışındaki şirketler başarılı olmaktadır. Maverick liderlik, diğer liderlik türlerine göre sıradışı olma özelliği taşımaktadır. Mevcut durumu muhafaza etmeyip, yenilikler peşinde olan bu yenilikleri de izleyicilerine uygulatmayı amaçlayan bu liderlerin ihtiyacı da teknolojik gelişmelerin farkında ve en iyi uygulayacıları olma özelliği taşıyan, 2000'li yılların temsilcisi Z kuşă̆g olarak adlandırılan kişilerin özelliklerini kapsamaktadır. Yeni fikir ve düşünce sahibi kişilerin şirketlere kazandırllması, istihdam edilmesi yalnızca kurumların değil, ülkelerin de ekonomik ve teknolojik açıdan rekabet avantajı sağlamasında etkili olacağı düşünülmektedir. Literatürde çok yetersiz sayıda maverick liderlik ile ilgili çalışma yer almaktadır. Bu çalışmada iş dünyasında yeni yer alan, Z kuşă̆ı temsilcisi bireylerin iş trenleri, tarzları ve maverick liderler ile olan ortak özellikleri de değerlendirilmiştir.
\end{abstract}

Anahtar Kelimeler: $\quad$ Maverick lider, teknoloji, Z Kuşağı. 


\title{
Maverick Leadership and Z Generation Review in Business
}

\begin{abstract}
Learders are people who guide people in every period and reach their goals. Communities choose leaders to make themselves better and prosper. Business are also seeking to find modern, contemporary leaders to ensure long-term sustainability and lasting customer relationships. Today, companies that can use technology in their institutions in the best way survive. Therefore, the leaders who manage these technologies best carry the companies to the future and are effective in the survival of organizations that are seen as living assets. In today's global competitive environments, companies with the understanding of meeting the needs of customers with different products and services are successful. Maverick leadership is extraordinary compared to other types of leadership. The need of these leaders, who do not maintain the current situation and aim to apply these innovations to their audience, is also the characteristics of the people named as $Z$ generation, representative of the 2000s, who are aware of technological developments and are the best practitioners. It is though that recruiting and employing new ideas and thoughts will be effective in providing economical and technological competitive advantage not only to institutions but also to countries. There are very few studies on maverick leadership in the literature. In this study, business trains, styles and common characteristics of young people of generation $Z$, who are new to the business world, were also evaluated.
\end{abstract}

Keywords: Maverick Leadership, Technology, Z Generation 


\section{Giriş}

Liderlik anlayışı toplumlarda, çoğunlukla liderlerin siyasi ve politik alanlardaki başarılarıyla ilgili özelliklerine göre sınıflandırılmış ve adlandırılmıştır. Oysaki liderlik sadece siyaset ve politikayla sinırlı kalmayıp, sanat spor, organizasyonlarda önem taşımaktadır. Son dönemlerde teknolojinin de önemi, belki de en çok tüm dünyayı etkileyen ve milyonlarca insanın ölümüne ve hastalanmasına neden olan Covid-19 adı verilen salgında anlaşılmıştır. Bu dönem dünyanın hemen hemen her bölgesindeki insanların evlerinden d1şarı çıkamamasına ve bütün işlerini, ihtiyaçlarını elektronik ortamda karşılamasina neden olmuştur. Teknolojik alt yapıya sahip ülkeler bu süreci daha kolay atlatmayı başarmışlardır. Ancak teknolojik alt yapıları olmayan ülkeler de ise ekonomik anlamda adeta çökme yaşamalarına neden olmuştur. Bu durum açıkça göstermiştir ki toplumların en önemli ihtiyacı, inovasyon ve teknoloji geliştirerek kriz dönemlerindeki olumsuz etkileri en az seviyede zararla atlatmaya çalışmaktır. Bu noktada şirketlerin en önemli ihtiyacı organizasyonlara yeni teknolojiyi getirerek çalışanlarıyla uygulayabilen liderlerdir. Maverick liderler, özellikle bu yönleriyle ön plana çıkmaktadır.

Şirketlerin yenilikler getirecek yirmi birinci yüzyılın ihtiyaçlarını ön görerek karşılayabilecek liderlere sahip olması gerekmektedir. Kurulurken ana sözleşmelerine süresiz, 99 yıl gibi ifadeler bulunsa da işletmeler ölümsüz olarak değerlendirilmemelidir. İşletmenin yaşam süresi, onu yöneten liderlerin işletmeye uzun süre yaşamını devam ettirebilecek yetenekleri kazandırmasıyla mümkün olacaktır (Ülgen ve Mirze, 2014, s.32). Organizasyonların devamlılığını sağlamak, küresel rekabet ortamlarında beklenin üzerinde kar elde etmek ve rekabeti karşılama durumuna gelmeleri için etkili ve verimli çalışma yöntemlerini uygulayacak başarılı liderlere ihtiyaçları bulunmaktadır. Bu noktada gerçekçi hedeflerle müşterilerin istek ve ihtiyaçlarını karşılamak her organizasyonların başarısında önem taşımaktadır.

Bu çalışmanın amacı, literatürde çok az sayıda yer alan ancak günümüzde özellikle iş dünyasında önemli yer tutan, sıra dışı ancak teknoloji ve inovasyon konusunda oldukça etkili olan maverick liderlerle ilgili konuların ön plana çıkarılarak organizasyonlarda bu tarz liderlerin yer almalarının değerlendirmeleri ve yeni dönemde iş yaşamında yer alacak olan z kuşağının eğilimlerini incelemektir. 


\section{Liderlik Nedir ve Özellikleri Nelerdir?}

Plato'dan bugüne insanlar liderlik üzerine bir çok değerlendirmeler yapmıştır. Dünyanın her yerindeki gerek eski dinozor yapılı gerekse yeni ekonomilerin ortaya çıkardığı yeni şirket gruplarında ortak şikayet, yeterli liderliğe sahip olunmadığıdır (Goffee, Jones, 2018). İş lideri, bireyleri harekete geçirebilen, az bilgiyle hızlı kararlar alabilen, inisiyatif sahibi, bilgili kişilerdir (Baltaş, 2016). Liderliğin belirli bir tanımı bulunmamaktadır. Ancak, mevcut tanımlamaların birçoğunda da şu varsayım yer almaktadır: Liderlik bireylerde kasıtlı bir etki bırakarak bir grup ya da organizasyonlardaki faaliyetlere ve ilişkilere yön vererek yapılandırma veya kolaylaştırmayı kapsayan süreçlerdir. Tablo 1' de liderlik tanımları bulunmaktadır (Yukl, 2018).

Tablo. 1. Literatürde Liderlik Tanimları

\begin{tabular}{llc}
\hline Yazar & Tanım & Yll \\
\hline $\begin{array}{l}\text { Hemphill } \\
\text { ve Coons }\end{array}$ & $\begin{array}{l}\text { Liderlik "Bir bireyin bir gruptaki faaliyetleri ortak bir hedefe yönlendirme da- } \\
\text { vranışıdır" }\end{array}$ & 1957 \\
\hline Katz ve Kahn & $\begin{array}{l}\text { Liderlik "Örgütün rutin direktiflerine mekanik itaatin üstündeki ve ötesindeki } \\
\text { itaatin düzeyidir" }\end{array}$ & 1978 \\
\hline Rauch ve & $\begin{array}{l}\text { Liderlik " Organize bir grubun faaliyet ve hedeflerini gerçekleştirme yönünde } \\
\text { etkileme sürecidir" }\end{array}$ & 1984 \\
\hline Rehling & $\begin{array}{l}\text { Liderlik "Bir vizyon ortaya koymak, değerlere hayat vermek ve bir şeylerin } \\
\text { Engle }\end{array}$ & 1986 \\
\hline Jacobs ve & $\begin{array}{l}\text { Liderlik "Ortak çabaya bir amaç (anlamlı bir yön) kazandırma ve amacı } \\
\text { Jaques }\end{array}$ & 1980 \\
\hline Schekleştirme yolunda istekli çaba uyarma sürecidir" & $\begin{array}{l}\text { Liderlik "Daha adaptif (uyarlanıcı) evrimsel değişimler başlatmak için, var } \\
\text { olan kültürün dışına çkma yeteneğidir" }\end{array}$ & 1992 \\
\hline $\begin{array}{l}\text { Drath ve } \\
\text { Palus }\end{array}$ & $\begin{array}{l}\text { Liderlik "insanların birlikte yaptıkları şeylere anlam kazandırarak onların } \\
\text { bunu anlamasını ve buna bağlanmasını sağlama sürecidir" }\end{array}$ & 1994 \\
\hline $\begin{array}{l}\text { Hause ve } \\
\text { Diğ. }\end{array}$ & $\begin{array}{l}\text { Liderlik "Bir bireyin diğer insanları örgüt örgütün başarısına katkıda bulunma } \\
\text { yönünde etkileme ve motive etme yeteneğidir" }\end{array}$ & 1999 \\
\hline
\end{tabular}

Kaynak: (Yukl, 2018).

ABD'de liderlik, bireysel bir süreç olarak değerlendirilir, paylaşılmaz ve kıskançlıkla muhafaza edilir. Japonya' da ise kolektif bir süreç olarak değerlendirilir ve paylaşılarak geliştirmeye gayret gösterilir. $\mathrm{ABD}^{\prime}$ de şirketlerinde yenilikçi fikirler genellikle üst yöneticiler tarafından ortaya çıkarılırken, Japon firmalarında fikirler, orta ve alt kademede görev alan çalışanlar tarafından üretilmektedir (Özel, 2016). Aşağıda teknoloji tarzı liderlik stili özellikleri yer almaktadır (Crawford, 2004): 
$\checkmark$ Teknolojik çözüm arar,

$\checkmark$ Değişimi uygulamak için doğrudan harekete geçer,

$\checkmark$ Kişisel metotlardan daha az etkilenir. Örneğin e-posta,

$\checkmark$ Yaptıkları son derece üretken özelliktedir,

$\checkmark$ Sert kişilik olarak algilanabilirler ancak sorun düzeltmede daha diplomatik çözümler bulabilirler.

\section{Maverick Liderlik}

Şirketlerde en önemli iki husus güven ve demokratik ortam sağlamaktır. Oysaki birçok şirkette yapılar otokrasiye dayalı olarak çalıştıklarından bu durum onların adeta bir tarih müzesine dönmesine sebep olmuştur (Lloyd, 1994). Literatürde, çok fazla yer verilmeyen, geleneksel karşıtı, toplum ve örgüt kurallarına uymakta zorlanan ve isteksiz olan liderler "Maverick Lider" olarak tanımlanmaktadır (Ünsar, 2016). McMurry (1974)' de maverick'i konformist olmayanlar olarak tanımlamıştır. Eksantrik, inatçı ve sebepsiz yere isyan çıkaran kişiler olarak ifade edilmiştir. Ayrıca bu kişiler, iktidarın tuzaklarına karşı endişeli, takıntılı, anksiyete özellik gösteren ancak bu nedenle de olağanüstü güdülü, cesaretli, iyimser, kararlılık gibi dikkate değer özelliklere sahip olan liderlerdir (Ray, Ugbah, Brammer ve Dewine, 1996). Maverick'lerin en önemli özelliği risk almaktır. En iyi örneği Sir Richard Branson'un riskli kararlar alarak, Virgin Atlantic lansmanı ile havayolu devi Bristish Airways'a meydan okumasıdır. Atlantic 1990'lı yıllarda önemli mali kayıplar yaşamasına rağmen dünyanın en karlı havayollarından bir olarak bilinmektedir (Gardiner ve Jackson, (2012).

Maverick liderler başarılı ve etkilidir. Organizasyonlarda değişim yaparlar. Bu değişiklikler ve dönüşümlerin yanında statükonun eylemsizliği nedeniyle çalışanlar, yeniliklerin yetenekleriyle üstesinden gelebilmesini sağlar (Crawford, 2001). Tesla Inc. Teknoloji şirketinin kurucusu ve CEO'su endüstriyel tasarımcı Elon Reeve Musk, Maverick tarzı liderliğin en iyi örneklerindendir. Musk, liderlik rolünü tam sahiplenerek kararlarda sorumluluğu üstlenmektedir. Gerçek maverick liderler, tutkulu, yaratıcı, merhametli ve kaprislidir. Bu bakımdan Musk'da maverick liderlik anlayışıyla, sahiplik ve önderlik yaptı̆̆ 1 
kişilere hizmet etmek için gerçek bir istek taşımaktadır (Cooper, 2018). Elon Musk'ın liderlik anlayışı şu şekildedir (Clifford, 2017):

1. Senden daha akıllı insanları işe al: Çözümün $\% 90^{\prime} 1$ harika insanları işe almakla başlar. Kişileri yanlış işe almak da size çok pahalıya mal olabilir.

2. Akışla gitme: Her trendi körü körüne takip etmeyin. Statükoyu sorgulayarak meydan okuyun.

3. Önce kuruluşunuza odaklanın: Ayrıntılarla fazla ilgilenmeden önce çalıştığınız konunun temel ilkelerini anladığınızdan emin olmasınız.

Alibaba grup' un kurucusu ve yönetim kurulu başkanı Jack Yun Ma 'da eticaretteki büyük başarısıyla adından söz ettirmiştir. Ekonomik başarısının yanı sıra duyarlı ve sorumlu bir lider kişiliği yansıtmaktadır. Jack Ma, farklı iş modelleri ve girişimcilik deneyimleriyle, tarzıyla, inançlarıyla olağanüstü kişiliği ile bilinmektedir (Lu, 2018). Donald Trump'ta ABD başkanlığa'na politikacı gibi değil iş lideri gibi düşünerek ulaşmıştır. Tek fikirli bir strateji izleyerek büyük bir vizyon ve misyon formüle etmiştir. Trump'ta statükoya meydan okuyan maverick liderdir (Poole, 2016). Uluslararası krizlerde diplomatik liderlerin üç özelliği ortaya çıkmaktadır bunlar; maverick, congregator ve pragmatist. Bu özelliklerin ortak noktası kurumsal baskılara direniş göstermek ve iyi varsayımlara meydan okumaktır. Maverick, krizin üstesinden gelinebilecek güçlü fikirler sunar ancak diğerlerine pek ilham vermez. Maverick, congregator ve pragmatist özellikler, farklı modlar ortaya çıkarır. Diplomatik liderlik yapmak için de önemli olan şey, risk alma, yaratıcı düşünmek ve değişen koşullara hızla uyum sağlamaktır (Bjola, 2015).

\section{Z Kuşağ}

Kuşak algısına yönelik olarak yapılan tanımlamalar farklılık göstermektedir. Kişiler arasındaki farklılıklar nedeniyle ortaya çıan kuşak/jenerasyon kavramları, tarih, psikoloji ve sosyal bilim alanlarında da araştırma ve çalışmaların ortaya çıkmasına neden olmuştur. Bu çalışmalar kuşakları, ülke ve kültürel değerlere göre; Gelenekselciler, Sessiz kuşak, Baby Boomer, X, Y ve son olarak da Z kuşağı olarak isimlendirilmiştir (Adıgüzel, Batur ve Ekşili, 2014). Bu kuşaklar doğum yıllarına göre sıralanırsa; 1946-1964 Baby Boomer; 19651979 X kuşağı; 1980-1999 Y Kuşağı; 2000-2021 yılları arasında doğanlar ise Z 
kuşağı olarak tanımlanmaktadır (Özgür, 2018). Bu kuşaklar arasındaki farklar, organizasyonların ekipleri işe alma ve geliştirmelerinde, değişimlerle başa çlkmalarında, motive etme süreçlerinde teşvik etme şekillerini de etkilemektedir (Jiri, 2016). Z kuşağı temsilcileri sosyal ağ ortamında büyüdüklerinden ve teknoloji onların kimliğini temsil ettiğinden dijital merkezlidirler. Bu nesli diğer nesillerden farkı da varlıklarının elektronik ve dijital dünyaya daha fazla bağlı olmasıdır (Singh ve Dangmei, 2016).

Z kuşağı özellikleri şu şekilde belirlenmiştir (Seymen, 2017) :

- Indigo ve kristal çocuklar: 2000 yılından sonra doğan Z kuşağı temsilcileridir.

- Teknoloji Çocukları: Teknolojinin içinde doğup yetiştikleri için teknolojiye çabuk adapte olurlar.

- Teknolojisi olmayan dünya bilmiyorlar: Teknolojiyle sürekli birlikte olduklarından bunun dışındaki dünyayı bilmezler.

- Bilgiye ulaşmaları kolaydır: Bilgiye kolayca ulaşarak elde edilen verileri bütüncül bir halde kullanabilirler.

- Farklı kültürleri öğrenme imkânı: Teknoloji vasıtasıyla elde ettikleri verileri işleyerek bütün dünya ile iletişim sağlamalarına ve birçok değişik insan, mekan ve kültürleri tanıma imkanına sahiptirler.

- İşte çalışmaya erken yaşta başlıyorlar: Monster Worldwide şirketi, Z kuşağındaki bireylerin lisede işe başlayarak üniversite yaşamında da çalışmaya devam ettiklerini tespit etmişlerdir.

- $X$ ve $Y$ Kuşağına göre uzun süre çalışmaktadırlar: $Z$ kuşağı," $X$ ve $Y^{\prime \prime}$ kuşaklarına oranla daha fazla çalışmaya isteklidir.

- Daha çok para kazanmak isterler: Mesai sonrası ve hafta sonları da çalışarak daha çok para kazanmayı isterler.

- Girişimcilik ruhları vardır: Z kuşağ1 temsilcileri, kısa sürede kendi iş yerlerini kurmak istediklerinden girişimcilik ruhuna sahiptirler.

- Teknoloji vazgeçilmezleridir: Z kuşağının \% 57'si teknoloji sayesinde kendilerini üretken bulduklarını ifade etmiştir. Yine Z kuşağının \% 39'u için akıllı cep telefonları, \%37'si için ise diz üstü bilgisayarlar kendileri için zaruri nitelik taşımaktadır (Eğitim caddesi, 2016 Aktaran: Seymen, 2017).

Z kuşağı temsilcisi bireylerin önceki nesillere göre fark1, kişisel olduğu kadar profesyonel beklentilerinin olmasıdır (Grow ve Yang, 2018). Z kuşağı iş 
yaşamına son katılan bireyler ve milenyum çocukları olarak, zengin dönemde büyüyen bireyler olarak tanımlanmaktadır. İş yaşamından yüksek beklentileri vardır ve dünyalarına anlam katmasını isterler. $Z$ kuşağındaki bireylerin, diğer kuşaklardan farklı olarak çok zengin (81\%) ve meşhur (51\%) olmaya yönelik hedefleri bulunmaktadır. Ayrıca bu kuşağı temsil edenler, sosyal sorumluluklara önem veren, farklılıklarla rahatça başa çıkabilen, teknolojiyi olağan görerek, elektronik olarak gruplaşan girişimci, sorgulayıcı eğilim gösteren bireylerdir (Robbins ve Judge: 149, 2015). ABD'de yer alan üniversite ve kolejlerdeki tam zamanlı çalışan öğrencilerin oranı 1970'li yıllarda \%34'lük seviyedeyken, 2006 'da \%46 oranına yükselmiştir. Son verilere göre ise $\mathrm{ABD}^{\prime}$ de $\% 81$ oranında öğrencinin yarı zamanlı işlerde görev aldıkları belirtilmiştir (Santrock, 2017).

\section{Z KUŞAĞI IŞ GIYIM TARZI}

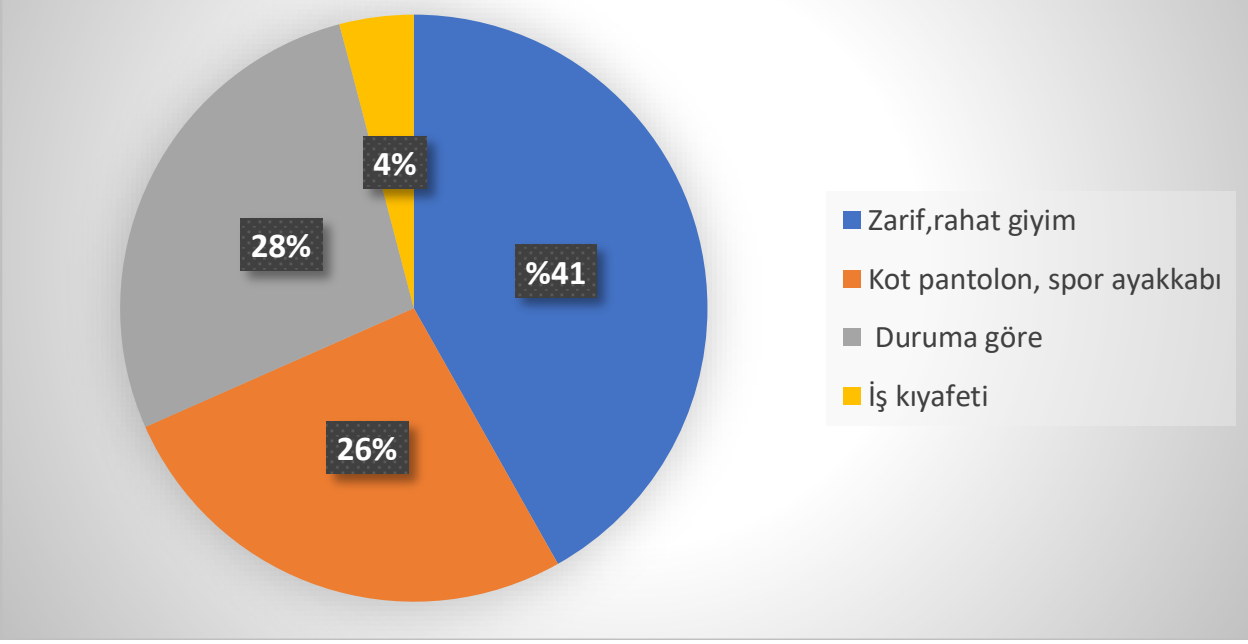

Şekil 1. Z Kuşağı İş Giyim Tarzı Kaynak: (Robbins ve Judge, 2015).

Şekil 1' de Z kuşağı iş giyim tarzına yönelik açıklamalar yer almaktadır. Z kuşağının kariyer görünümü ve özelliklerine ait değerlendirmeler aşağıdaki gibidir (Singh, 2014):

- Özgürlük: Z kuşağı bireyleri, her zaman sorumluluklarını ve ne yapacaklarını bilirler. Bu nedenle çalışma saatleri, izinler konusunda 
endişe duymayacak bir şirkette çalışmak isterler. Yöneticilerinin patron görünümü dışında arkadaş gibi olmalarını isterler.

- Alışılmadık: Geleneksel mesleklerde bile yeni fırsatlar görerek yeni şeyler yapabilme yeteneklerini değerlendirebilirler.

- Materyalizm: Z kuşağı temsilcileri, kendi yaşantılarını gerliştirmek için kariyer yapmayı fursat olarak görürler. İyi bir arabaya sahip olmak, Avrupa'ya tatile gitmek gibi "iyi bir yaşam"sembollerine karşı ilgi duyarlar ancak gösteriş yapan kişilere de karşıdırlar.

- Küresel: Z kuşağı temsilcileri yurtdışında eğitim alarak küresel iş piyasalarındaki gelişmeleri ve değerleri aşılamak isterler.

- Mesleki Bağlılık: Z kuşağı, profesyonel mesleki bağlılığı ön koşul olarak görmezler.

- Teknoloji: Z kuşağının mobil, bilgi işlem ve bilgisayar teknolojisini en iyi bilen nesil olduğu önemli bir faktördür.

\section{Maverick Liderlik ve Z Kuşağı}

Liderlik kavramından bahsetmek için liderin formal özellikte yani resmi, şekli biçimsel özellikler ve yetkilerle donatılmış olması gerekmemektedir. Bu tür yetkileri olmadan önemli orandaki grupları etkileyerek belirli davranışlara yönlendirebilen liderler var olduğu gibi aksine, çok daha fazla formal yetkileri bulunmasına rağmen etkili bir şekilde kullanarak grupları etkileyemeyen liderler de olabilmektedir (Koçel: 671, 2016). Girişimcilik şirketleri yenilemenin canlı tutmanın özünü oluşturmaktadır. Yapılan birçok inovasyon kaynağ da yeni teşebbüs girişimciliğini temsil eder. Fursat yakalama kaynaklar ve kilit insanlarla elde edilir. Yeni girişimleri başarıya ulaştırmak için teknik ve iş becerilerini kilit karakteristik özelliklerle bir araya getirmek gerekmektedir (Pearce ve Robinson, 2015). Tam bir teknoloji çocuğu olarak nitelendirilen Z kuşağına "Dijital Yerliler" tanımı uygun olabilir. Çünkü insanlık tarihindeki el, yüz, kulak gibi motor becerileri en iyi senkronize edebilen nesildir. Yaratıcılıklarını ortaya çıkaracak faaliyetlerden hoşlanırlar ve sonuca odaklıdırlar. Çok diplomalı, uzman ve buluşçu yeteneklere sahiptirler (Özgür, 2018). Maverick liderler de yenilikçi işlere heveslidirler. Gelenekleri tersine çeviren ve bunu yerine yıkıcı fikir ve yenilikçi kişiler ararlar. Maverickler, her alanda ve büyüklükteki organizasyonlarda dört önemli zorlukla uğraşırlar. Bunlar; strateji belirlemek, yeni fikirleri ortaya çıkarmak, müşteri 
ilişkileri sağlamak ve en iyi insanların harika sonuçlar elde etmelerine yardımcı olmak (Burkhardt, 't. y'.). Z kuşağı ise sanal ya da yüz yüze iletişimde olan başarıları, işverenlere karşı son derece sadakatleri ve yaratıcı kapasiteleri ile maverick liderlerin tamamlayıcı bireyleridir (Harris, 2020).

\section{Tartışma ve Sonuç}

Maverick liderlerin genel anlamda kurallara uymama konusunda eğilimleri bulunsa da yaratıcı bireyleri harekete geçirebilen yapıları sebebiyle inovasyona yönelik organizasyonlarda önemli yarar sağlamaktadır (Ünsar, 2016). Liderin operasyonel yetenek geliştirmeyle ilgili genç yöneticilere rol model olarak hizmet etme sorumluluğu bulunmaktadır. Bunun nedeni ise, örnek davranış ve alışkanlıklar sayesinde gençlerin herhangi bir konuda karar verirken öğrendikleri bu anlayışı içgüdüsel bir hareket olarak sergileyebilmesidir (Pearce ve Robinson, 2015).

Radikal fikir ve düşünceler, Ar-Ge laboratuvarlarında veya bilim insanlarının ve girişimcilerin akıllarından ortaya çıkmaktadır (Luecke, 2011). Genel olarak şirketlerin en büyük ve önemli eksiği teknolojiyi yeteri kadar kullanamama sorunudur. Gerek kaynak yetersizliği gerekse uzman eksikliği organizasyonların rekabetle başa çıkamalarına engel olmaktadır. Tüm dünyada yaşanan beklenmeyen krizler şirketleri ekonomik anlamda etkileyebilmektedir. Ancak, bu krizlere karşı proaktif olarak önlem alan şirketler ayakta kalmayı başarabilmektedir.

Genel anlamda maverick liderler, kendi gayretleri, çabaları ve girişimcilik ruhlarıyla başarıyı sağlayan kişilerdir. Bu liderler, diğerlerinden farklı olarak teknoloji ve niş odaklı piyasaların gelişiminden yararlanarak yaratıcı fikirlerini sergilemektedir. Şirketlerin günümüz küresel rekabet süreçlerinde maverick liderlerin bilgi, beceri ve yeteneklerini organizasyonlarda paylaşımına imkân sağlamalarının ülkelerin teknoloji gelişimi açısından da önemli katkıda bulunabilir. Ekonomik ve küresel değişimlerin etkilerini yaşayan $\mathrm{z}$ kuşağı temsilcisi bireyler de sorumluluk üstlenerek hızlı bir şekilde iş dünyasında yer alarak liderlik etmeye hazırlıklıdır. Ayrıca bu kuşağın temsilcileri, önceki nesillerden farklı olarak şirketlerin ihtiyacı olan motive edici faktörlere sahip bireylerdir (Gaidhani, Arora ve Sharma, 2019).

Özellikle tüm dünyada 2000'li yıllar sonrasına damgasını vuran dijital çağ, konvansiyonel liderlik kurallarını da değiştirmiştir. Artık önümüzdeki 
yıllarda liderlerde, farkılılık yaratan girişimcilik becerisi, dijital yetenekler, güçlü network kurma ve sağlam işbirlikleri ile vizyon sağlayarak katılımcı toplayabilme becerisine sahip olma özellikleri beklenmektedir (Toduk, 2014).

"Lider olmak, borsada başarılı bir yatırım yapmak gibidir; eğer bir gün içinde servet kazanma peşindeyseniz başarılı olamazsını" Bu nedenle önemli olan uzun bir sürede gün gün yaptıklarınız, risk almanız ve iyi değerlendirmenizdir (Maxwell, 2013). Bu bağlamda Z kuşağ temsilcisi bireylerin, risk alma konusunda büyük başarı gösteren maverick liderlerin özelliğini taşımakta olduğu ve geleceğe yönelik olarak bu tarz liderlerin işletmelerde yer alacağ düşünülmektedir. Bu nedenle $\mathrm{Z}$ kuşağ bireylerin bilgi, yetenek ve becerilerini geliştirme ve fikir ve düşüncelerini paylaşma imkânı oluşturulmalıdır. Literatür incelendiğinde sınırlı sayıda yer alan maverick liderlik ve Z kuşağı bireylerinin özelliklerine yönelik analitik çalışmaların yapılması literatüre önemli katkı sağlayacağı gibi, işletme yönetimlerine de farklı bir bakış açısı kazandıracağı düşünülmektedir. 


\title{
EXTENDED ABSTRACT
}

\section{Maverick Leadership and Z Generation Review in Business}

\author{
* \\ Ayla Avc1 \\ İstanbul Sabahattin Zaim University
}

They need successful leaders who will apply effective and efficient working method order to ensure the continiuity of organizations to gain more than expected profit in global competitive environments and to meet the competition.

Since Plato, people have made many evaluations on leadership. The common complaint in new corporate groups around the world both with old dinosaur builds and new economies in the lack of leadership (Goffee, Jones, 2018). Business leaders are knowledgeable people who can mobilize individuals make quick decisions with little information have initiative and knowledge (Baltaş, 2016). Leadership in the USA is considered an individual process, not shared and preserved with jealousy. In Japan, it is evaluated as a collective process and efforts are made to develop it by sharing. While in the USA, innovative ideas are usually created by top managers in companies, in Japan companies, ideas are producted by employees working at middle and lower levels (Özel, 2016).

Leaders who are not given much space in the litarature, who are anti-traditional who have difficulty in obeying the rules of society and organization and who are unwilling are defined as "Maverick Leaders"(Ünsar, 2016). Maverick leaders are successful and effective. They make changes in organizations. Besides these changes and transformations due the inaction of the status quo, employees ensure that innovations can cope with their skills (Crawford, 2001). Tesla Inc. Elon Reeeve Musk, industrial designer and founder and CEO of the technology company is a prime example of Maverick-style leadership (Cooper, 2018). In Donald Trump, The US reached the presidency by thinking like a business leader not a politician. He followed a single minded strategy and formulated a great vision and mission. Trump is the leader who challenges the status quo (Poole, 2016). 
Three characteristics of diplomatic leaders emerge in international crises, maverick, congregator and pragmatist. What these traits have in common is to resist institutional presssures and challenge good assumptions. Maverick, congregator and pragmatist features reveal different mods. Also important for diplomatic leadership is to take risks think creatively and quickly adapt to changing conditions (Bjola, 2015).

Definitions made for the perception of generation differ. The concepts of generation that emerged due to the differences between people have led to the emergence of history, psychology and social sciences. These studies are based on generations country and cultural values; named as the traditionalists, silent generation, baby boomer, $\mathrm{X}, \mathrm{Y}$ and finally $\mathrm{Z}$ generation (Adigüzel, Batur ve Ekşili, 2014).

Generation Z, representatives are digitally centric as they grow up in the social networking environment and technology represents their identity. The difference of this generation from other generations is that their existence is more connected to the electronic and digital world (Singh ve Dangmei, 2016). They have high expectations from business life and want to add meaning to their world. Individuals in the generation $\mathrm{Z}$ may become very rich $(81 \%)$ and famous $(51 \%)$, unlike other generations. In addition the representatives of this generation are entrepreneurial questioning individuals who attach importance to social responsibilities can easily cope with differences see technology as normal and group electronically (Robbins ve Judge: 149, 2015).

The leaders to talk about the concept of leadership the leader does not have to be formal that is with formal characteristics and authorities. There are leaders who can direct certain behaviors by influencing a significant number of groups without such authority but on the contrary there may be leaders who cannot influence groups by using them effectively despite having much more formal authority (Koçel: 671, 2016). The definition of "Digital Locals" may be appropriate for generation $\mathrm{Z}$, who is considered a complete technology kid. Because is the generation that can best synchronize motor skills such as hand, face and ears in human history. They enjoy activities that reveal their creativity and are result-oriented. They are highly qualified expert and intentive (Özgür, 2018). Maverick leaders are also eager for innovative jobs. They look for ideas and innovators who reverse traditions and replace it. Mavericks, tackle four key challenges in organizations of all areas and sizes. These; strategizing coming up with new ideas providing customer relationships and 
helping the best people achieve great results (Burkhardt, 't. $y^{\prime}$.). Generation Z are complementary individuals of maverick leaders with their success in virtual or face-to-face communication their utmost loyalty to employers and their creative capacity.

Althought maverick leaders generally have a tendency to not obey the rules they provide significant benefits in organzations for innovation due to their structures that can mobilize creative individuals (Ünsar, 2016). In this context, it is thought that the individuals representing the generation $\mathrm{Z}$ are the maverick leaders who have shown great success in taking risks and such leaders will take place in the business fort he future.

\section{Kaynakça / References}

Adıgüzel, O., Batur, Z. H. ve Ekşili, N. (2014). Kuşakların değişen yüzü ve Y kuşağ ile ortaya çıkan yeniç̧alışma tarz: Mobil yakalılar. Süleyman Demirel Üniversitesi Sosyal Bilimler Enstitïsü Dergisi, 1(19).

Baltaş, A. (2016). Türk kültüründe yönetmek. İstanbul: Remzi Kitabevi. 9. Basım.

Bjola, C. (2015). Diplomatic leadership in times of international crisiss: The Maverick, the congregator and the pragmatist. The Hague Journal of Diplomacy, 10(1), 4-9.

Burkhardt, V. ('t.y'). The Maverick Spirit. 12. 06. 2020 tarihinde https://www.ideaconnection.com/interviews/00030-The-Maverick-Spirit.html adresinden erişilmiştir.

Clifford, C. (2017). Elon Musk's 3 best pieces of advice for how how to be a great leader? CNBC. 12. 07. 2020 tarihinde https://www.cnbc.com/2017/06/20/elon-muskhow-to-be-a-great-leader.html adresinden erişilmiştir.

Crawford, C. B. (2001). Leadership and innovation: Champions and techies as agents of influence. A paper presetend to the Assocation of Leadership Educators 2001 Conferance Review Committee.

Crawford, C. B. (2004). Faces of leadership in an age of innovation. A quarterly publication of the Ohio State University Leadership Center, 1-2.

Cooper, K. (2018). The pros and cons of "Maverick" leadership. 12.07.2020 tarihinde https://www.hrzone.com/community/blogs/kate-cooper/the-pros-and-cons-ofmaverick-leadership adresinden erişilmiştir.

Gardner, E., ve Jackson, J. C. (2012). Workplace maverciks: How personality and risk-taking propensity predicts maverickism. The Bristish Psychological Society. 103, 497519 .

Gaidhani, S., Arora, L., veSharma, K. M. (2019). Understanding the attitude of generation $\mathrm{z}$ towards workplace. International Journal of Management, Technology and Engineering, $9(1)$. 
Goffee, R. , ve Jones, G. (2018). Liderlik HBR'S10 must reads. içinde. Insanlar liderliğinize ne diye gerek duysun?. 107-131.

Grow, J. M., ve Yang, S. (2018). Generation -Z enters the advertising workplace: expectations through a gendered lens. Journal of Advertising Education, 22(1).

Harris, K. (2020). A new generation of workers: Preparing for generation Z in the workplace. Senior Theses. 335.

Jiri, B. (2016). The employees of baby boomers generation, Generation x, generation y, and generation $\mathrm{z}$ in selected Czech Corporations as conceivers of development and competitiveness in their corporation. Journal of Competitiveness, 8(4), 105-123.

Koçel, T. (2016). İşletme yöneticiliği. İstanbul: Beta Basım. 16. Baskı.

Lloyd, B. (1994). Maverick! An alternative approach to leadership, company organization and management. Leadership E Organization development Journal, 15(2).

Lu, Y. (2018). Lessons from "Crazy Jack": An extraordinary leader in style and beliefs. 15.

05. 2020 tarihinde https://leaderonomics.com/business/5-leadership-lessonsfrom-jack-ma adresinden erişilmiştir.

Lucke, R. (2011). Iş dünyasında yenilik ve yaratıcılı. (Çev Ed. Parlak, T.) İstanbul: Türkiye İş Bankası Kültür Yayınları. 2. Basım.

Maxwell, C. J. (2013). Liderlik yasalar. İstanbul: Beyaz Yayınları.

McMurry, R. (1974). The maverick executive. New York. American management Association.

Özel, M. (2016). Stratejik liderlik. İstanbul: Küre Yayınları.

Pearce, A. J. ve Robinson, B. R. (2015). Stratejik yönetim. Ankara: Nobel yayın. (Çev. Ed. Barca, M.) 12. Basım çeviri.

Poole, E. T. (2016). Donald Trump is maverick leader, but you can disturp in other ways. Real Business. 20. 06. 2020. https://realbusiness.co.uk/donald-trump-maverickleader-can-disrupt-other-ways/adresinden erişilmiştir.

Ray, G. R., Ugbah, D. S., Brammer, C. ve Dewine, S. (1996). Communication behaviors, innovation, and the Maverick Leader. The Journal of Leadership Studies, 3(3).

Robbins, S. P. ve Judge, A. T. (2015). Örgütsel davranıs. Organizational Behavior. (Çev. Ed. Erdem, I.) Ankara: Nobel yayın. 14. Basımdan çeviri.

Santrock, J. W. (2017). Yaşam boyu gelişim psikolojisi. (Çev. Ed. Yüksel, G.). Ankara: Nobel yayin.

Seymen, F. A. (2017). Y ve Z Kuşak insanı özelliklerinin Millî Eğitim Bakanlığı 2014-2019 stratejik programı ve TÜBiTAK Vizyon 2023 Öngörüleri ile İişkilendirilmesi. Kent Akademisi Dergisi, 10(4).

Singh, A. (2014). Challenges and issues of generation z. Journal of Business and Management (IOSR-JBM), 16(7), 59-63. 
Singh, A. P., and Dangmei, J. (2016). Understanding the generation z: The future workforce. South-Asian Journal of Multidisciplinary Studies (SAJMS), 3(3).

Özgür, M. G. (2018). Kuşak çatışması. [Blog yazısı]. 12. 06. 2020 tarihinde https://gulsahmeralozgur.dr.tr/kusak-catismalari-x-y-z/ adresinden erişilmiştir.

Ülgen, H. ve Mirze, K. S. (2014). İsltemelerde stratejik yönetim. İstanbul: Beta Basım. 7. Baskı. Ünsar, A. S. (2016). Liderlik üzerine güncel yazılar. İstanbul: Paradigma Akademi.

Toduk, Y. (2014). 2023 lideri dijital çağın liderlik sırları. İstanbul: Doğan yayıncllk.

Yukl, G. (2018). Örgütlerde liderlik. (Çev Ed. Çetin, Ş. ve Baltacı, R.). Ankara: Nobel Yayın. 8. Basımdan çeviri.

\section{Kaynakça Bilgisi / Citation Information}

Avc1, A. (2020). İş dünyasında Maverick liderlik ve Z kuşağı incelemesi. OPUS-Uluslararası Toplum Araştırmaları Dergisi, 16(32), 5377-5392. DOI: $10.26466 / o p u s .771231$ 